\title{
Lisboa em transição profunda e desequilibrada. Habitação, imobiliário e política urbana no sul da Europa e na era digital
}

\author{
Lisbon in deep and unbalanced transition. Housing, real estate \\ and urban policy in the south of Europe and in the digital era
}

João Seixas [l]

Simone Tulumello [II]

Giovanni Allegretti [III]

\begin{abstract}
Resumo
Lisboa encontra-se em transição. Ao sair de uma crise económica acompanhada por severas políticas de austeridade, encontra-se numa nova fase de dinamismo económico, mas sem conseguir inverter antigas e novas estruturas de desigualdade social e territorial. Este artigo, ao mostrar as recentes transformações do mercado imobiliário e da habitação na principal cidade portuguesa, bem como os movimentos sociais preocupados com o direito à habitação, questiona as articulações entre desenvolvimento local e modelos da nova economia global. A recente história de Lisboa é apresentada como caso paradigmático das disputas entre modelos pseudoliberais de desenvolvimento económico e urbano, e a paulatina formação de suas contestações locais, sobretudo sociais mas também institucionais e, decerto, crescentemente interligadas em redes internacionais.
\end{abstract}

Palavras-chave: movimentos sociais; direito à habitação; direito à cidade; políticas urbanas; Portugal.

\begin{abstract}
Lisbon is undergoing deep transformations. After an economic crisis accompanied by harsh austerity policies, Lisbon is experiencing a new economic dynamism, but without reverting old and new, social and territorial, inequalities. This article presents recent transformations in the real estate market and housing of the main Portuguese city, and portrays emerging social movements concerned about the right to housing. In addition, it questions the articulations between local development and models of the new global economy. Lisbon's recent history is shown as a paradigmatic case of clashes among pseudo-liberal models of urban and economic development, and the gradual emergence of forms of contestation, with both social and institutional natures, at the local level but increasingly connected to international networks.
\end{abstract}

Keywords: social movements; right to housing; right to the city; urban policies; Portugal. 


\section{Introdução}

Lisboa, junho de 2018. Sucedem-se, ao longo desse mês das festas da cidade, uma multiplicidade de notícias e de situações com epicentro territorial ou político na capital portuguesa, resultantes de importantes tendências com evolução incremental:

1) A cidade de Lisboa é premiada no "Europe's Leading City Destination" nos prémios da World Travel Awards. No ano anterior, a cidade havia sido eleita como o "Melhor Destino Mundial para City Breaks". As distinções, apesar de simbólicas, têm refletido nos números do mercado turístico da cidade.

2) Os dados do ano de 2017 registraram mais de 20 milhões de hóspedes no país, correspondendo a cerca de 60 milhões de diárias em hotéis. 0 mercado do turismo representava quase $10 \%$ do PIB nacional, correspondendo a cerca de $50 \%$ das exportações de serviços e a mais de $15 \%$ das exportações totais. Nesse contexto, o turismo urbano vem afirmando-se claramente como o segmento em maior crescimento no país.

3) Segundo o relatório de junho da Confidencial Imobiliário, ${ }^{1}$ as expectativas de valorização dos investimentos imobiliários turísticos situavam-se em torno de 7,1\%/ano (veja-se quando comparadas com uma média de $3-4 \%$ dos investimentos em habitação). Entre os elementos em maior crescimento, como resultado da rápida mutação para uma economia de intermediação digital, o destaque mantinha-se nos apartamentos de short rental (arrendamento de breve duração). Os dados da plataforma "AirDNA"2 apresentavam para o município central de Lisboa, em junho de 2017, um número de apartamentos em short rental já superior a 14 mil,
$80 \%$ destes correspondiam a casas inteiras, demonstrando a profissionalização do sector e a desmistificação da perspectiva da habitação partilhada, pelo menos em termos turísticos. 0 rácio de número de apartamentos turísticos em face do número total de apartamentos, no município de Lisboa, mostrava ser practicamente 0 dobro que em Barcelona (4,5\% ante 2,5\% respectivamente); verificando-se o mesmo tipo de pressão noutros indicadores sintéticos similares, tais como o número de hospedagens turísticas, diante do número de residentes $(21,5$ ante 14,5 , respectivamente).

4) 0 índice de valorização das rendas residenciais, atualizado pelo Instituto Nacional de Estatística (INE, 2018), registrava um aumento anual homólogo de cerca de 18\%. Essa evolução era corroborada pela Confidencial Imobiliário, que informava uma variação para o centro de Lisboa superior a 100\% em face dos níveis de 2011; e um índice global de 140\% para toda a cidade; num aumento incremental que atingia uma variação da renda imobiliária, para todo o país, de $14,2 \%$ em relação ao ano anterior (ibid.). 0 número de casas em pipeline de licenciamento habitacional para a cidade aumentava $60 \%$ ante $o$ ano anterior (ibid.).

5) Por seu lado, o relatório de Estabilidade Financeira do Banco de Portugal (2018) revelava, pela primeira vez, uma relevante preocupação pública pela crescente vulnerabilidade e endividamento das famílias em face dos aumentos das rendas registados no mercado imobiliário.

6) A Câmara Municipal de Lisboa (CML) anunciava a entrega de meia centena de casas municipais reabilitadas e com renda apoiada para moradores do centro histórico, no âmbito do programa "Habitar o Centro Histórico", reflectindo, assim, o início operacional do mais 
amplo Programa de Renda Acessível (PRA) cujos objetivos comportam a entrega de cerca de 7 mil unidades habitacionais até ao ano de 2021, num forte investimento público (sobretudo na disponibilização de património municipal) e sustentado na contratualização com investimento privado num valor global superior a 700 milhões de euros. $^{3}$

7) A CML assumia, entretanto, a sua participação no grupo de cidades - que inclui Berlim, Barcelona, Cidade do México, Londres, Nova York, Montevideo, entre outras - que iria, no mês seguinte, assinar publicamente na sede das Nações Unidas, em Nova York, a declaração "Cities for Adequate Housing". ${ }^{4}$ A criação dessa rede revelava preocupação pública e internacional pela situação de crescente pressão sobre os mercados urbanos da habitação; e exigia maior atenção global a essas realidades, bem como mais poderes, instrumentos e capacidade política para poderem actuar de forma mais enérgica.

8) Entretanto, na Assembleia da República Portuguesa, e já desde o ano anterior, debatiam-se e propunham-se alterações a diplomas de elevada relevância para os mercados imobiliário, habitacional e turístico nacional. A perspectiva que se ia materializando era a do reconhecimento das elevadas pressões sobre a habitação; mas conjugada com uma necessidade de manutenção da recuperação económica e dos investimentos externos.

9) Practicamente todos os dias, nos jornais e nos mais diversos encontros, conferências e congressos sobre a habitação e o mercado imobiliário, os agentes económicos - e também muitos políticos - vão continuamente referindo que não se deveria criar excessiva instabilidade nos mercados, com o risco do afastamento dos investimentos e da consequente recuperação económica e urbana.

Todos esses anúncios e fenómenos, crescentemente interligados e provenientes de uma economia urbana em profunda transformação desde pelo menos o início da década de 2010 (Seixas et al., 2015), parecem convergir cada vez mais para uma situação de charneira, em termos de sérias decisões políticas - de política urbana, seguramente, mas também de política económica e mesmo de modelos mais globais de progresso.

Este texto visa refletir sobre a condição presente de Lisboa: uma metrópole em profunda transição, que, ao procurar sair de uma forte crise económica - acompanhada por severas políticas de austeridade impostas pelo Estado nacional e pelas próprias instituições Europeias -,encontra-se agora numa nova fase de dinamismo económico; sem, porém, ainda conseguir inverter quer antigas, quer novas estruturas de desigualdade, tanto sociais como territoriais.

Ao mostrar os recentes impactos no mercado imobiliário e da habitação na principal cidade portuguesa, provindos estes da conjugação de transformações globais com políticas e evoluções de base local, reflete-se em torno das transformações, de tempos longos, nas paisagens e estruturas socioespaciais de todo um sistema urbano. Sendo essa evolução de Lisboa evidentemente específica, enquadra-se, no entanto, nos padrões de evolução mais globais dos modelos de desenvolvimento e de progresso e da nova economia, bem como das mutações nas influências urbanas decorrentes de processos em evidente carência de capacidade de acção e de regulação política. A recente história da cidade de Lisboa, em profunda, 
mas desequilibrada transição, é (no nosso entender) um caso paradigmático das crescentes disputas - com incertas evoluções, por serem dependentes de determinados fatores também em evolução - entre novos modelos pseudoliberais de desenvolvimento económico e urbano e a paulatina formação de suas contestações, de base local e, sobretudo, social, mas também institucionais e, decerto, crescentemente interligadas em redes europeias e mesmo globais.

0 nosso argumento desenvolve-se por seis seções. Primeiro, apresentaremos o contexto político e económico português em transição, especialmente no novo período de "fim da austeridade" desencadeado com a mudança de governo em 2015. Segundo, apresentaremos as caraterísticas principais dos sistemas e mercado de habitação em Portugal; necessárias para compreender, em terceiro ponto, as transformações dos últimos anos decorridas em Lisboa e apresentadas - em relação com o contexto metropolitano e nacional - seguidamente. Quarto, focalizaremos a atenção sobre os novos movimentos sociais que emergem na conjugação das novas condições urbanas com as evidentes pressões sobre o sistema de habitação. Quinto, analisaremos em maior reflexividade, o campo das políticas e seus potenciais movimentos de abertura e de ausência, bem como as contradições inerentes nas respostas às dinâmicas políticas e dos próprios movimentos sociais. Em sexto e conclusivo ponto - que assumimos "em movimento" -, refletiremos sobre as possíveis tendências perante essa cidade em plena fase de vertiginosa transição sociopolítica.

\section{0 fim da austeridade?}

Em comparação com outros países da Europa Ocidental, Portugal - nos últimos anos - tem seguido uma trajetória peculiar e em mudança muito acelerada. As eleições políticas de 2015, e uma centralidade renovada da política parlamentar desde então, levaram o país a uma experimentação governamental quase única na Europa, que foi denominada - com um termo inicialmente destinado a ser depreciativo e depois apropriado pelos próprios esquerdistas -"geringonça". 0 termo, que se refere a uma espécie de mecanismo muito intrincado e complicado de gerenciar, intenta fotografar a incomensurabilidade de visões da coligação (composta pelos partidos socialista e comunista, os verdes e o Bloco de Esquerda) que apoia o governo socialista liderado por António Costa, antigo presidente da Câmara de Lisboa. A aliança - involuntariamente facilitada e cementada pela hostilidade mostrada por ela pelo então Presidente da República Cavaco Silva - de alguma forma traz as consequências de uma reflexão que se produziu numa esquerda tradicionalmente fragmentada e litigiosa (Freire, 2017) sobre a necessidade de empenhar-se em conjunto para reverter o aumento das desigualdades trazido pelas políticas "austeritárias" 5 forjadas a partir do acme da crise económico-financeira que atingiu o país a partir de 2008.

0 novo clima político, juntamente com os efeitos da flexibilização de algumas das medidas de austeridade introduzidas desde 2010 e especialmente durante o chamado "resgate externo" de Portugal, ${ }^{6}$ tem sugerido, a muitos cidadãos e observadores, que Portugal acabará 
em breve por deixar para trás a pior parte das suas políticas austeritárias.

0 mainstream austeritário dominou (bem além das clivagens partidárias) vários anos da visão política nacional, mas nunca foi totalmente aceito pela maioria dos atores de nível local da administração do Estado e por grande parte da opinião pública. ${ }^{7}$ De facto, muitos observadores têm sublinhado que a receita de austeridade demonstrou ser ineficiente e injusta para lidar com a crise econômica e financeira, sendo, afinal, uma das principais causas da profunda recessão após 2011 (Pedroso, 2014). Além disso, o consenso austeritário trouxe consigo uma falta generalizada de autonomia política para o país, particularmente no que diz respeito aos credores externos (Abreu et al., 2013). 8

Apesar das expectativas elevadas e da perceção de muitos cidadãos (revelada por várias pesquisas; ver Ferreira, 2018) de que as promessas de recuperação e estabilização tenham sido parcialmente cumpridas, mudar radicalmente seis anos de políticas austeritárias não se tem revelado uma tarefa fácil. De facto, a maioria das reformas aprovadas durante o período de triunfo da austeridade não foi revertida ou transformada integralmente ${ }^{9}$ e continua a orientar consideravelmente as direções de desenvolvimento do país. Mesmo com o apoio substancialmente favorável da comunicação social nacional e do uso inteligente do aparato de comunicação do governo, o crescimento econômico relativo que o país desfrutou durante os últimos anos (principalmente baseado em receitas procedentes de recursos financeiros externos ligados a turismo e imobiliário) poderá não durar para sempre. Há quem diga que a retomada atual seja um alívio "aparente" e não esteja a conseguir enfrentar os problemas estruturais do país, incluindo a alta e crescente desigualdade e as fraquezas estruturais do estado de bem-estar.

Teles (2018), por exemplo, realça como a economia portuguesa - apesar de não ter ultrapassado "um dos maiores níveis de endividamento do mundo (público e privado)" mantém-se fortemente dependente de fluxos financeiros estrangeiros, assim que "uma nova crise financeira é apenas uma questão de tempo". Para o investigador, Portugal tem-se tornado "um estudo de caso sobre a compatibilidade de políticas antiausteridade e metas fiscais europeias", e a maioria dos comentaristas associa a recuperação do dinamismo económico e da capacidade de fazer frente aos devidos pagamento dos empréstimos estrangeiros "ao aumento do consumo interno, impulsionado pela reversão dos cortes salariais e previdenciários" que tem sido capaz de aumentar a receita tributária e diminuir gastos sociais como aqueles ligados ao seguro-desemprego. Porém - defende o autor, que sufraga as suas hipóteses com dados produzidos pelo Observatório Português sobre Crises e Alternativas $\left(\right.$ CRIS-ALT) ${ }^{10}$ - esse reequilíbrio da receita "não se traduziu em mais investimentos no setor público [que representam] um dos principais pontos cegos do acordo do governo de coalizão". ${ }^{11}$ Nesse quadro, os serviços públicos ainda estão amplamente sujeitos às normas de austeridade, permanecendo "cronicamente insuficientes e subfinanciados".

Aceitando essa visão, a redução dos défices fiscais acumulados poderia ser explicada por uma combinação de aumento da receita tributária, ganhos financeiros e restrições de gastos públicos. Uma parte primordial da redução 
de gastos públicos (que vai afetando quer as finanças públicas quer as privadas) seria devido à súbita mudança das condições financeiras internacionais para a economia portuguesa, propiciada pelo programa Quantitative Easing (QE) de compra de obrigações do $B C E$, que tem favorecido a descida das taxas de juro ${ }^{12}$ e evitado uma crise bancária sistêmica, num país onde os balanços dos bancos ainda estão afetados por níveis de inadimplência entre os mais altos da zona do euro (13,3\%), apenas depois da Grécia e de Chipre. Portanto, a recuperação econômica portuguesa pode estar ocorrendo em "areias movediças", ${ }^{13}$ ou seja, num terreno "volátil", viciado pela positiva combinação de uma moderada recuperação económica geral da Europa e da política não convencional de QE. Assim, é difícil defender que "a retórica antiausteridade compatível com a Europa" corresponda aos reais desafios políticos para uma sólida reestruturação da economia portuguesa que não seja apenas centrada "nos sectores de baixa produtividade, atormentados pela precariedade e com pouca necessidade de novos investimentos" (Teles, 2018).

Poderá esse quadro mudar em breve? Dar uma resposta que não seja apenas baseada na confiança (ou na desconfiança) absoluta nos atuais governantes é, francamente, difícil. Sólidas mudanças de políticas dependem de muitos factores, incluindo a capacidade das cidadãs e dos cidadãos - assim como dos seus movimentos e coletivos sociais organizados (incluindo partidos e sindicatos) - de lutar para obter uma mudança substancial das políticas, assim como um convencido abandono da substancial continuidade com várias das políticas forjadas na fase de governação austeritária.
Nesse sentido, é importante, no entanto, sublinhar o fato de que os problemas de longo prazo e a longa onda de políticas de austeridade têm vindo a coexistir, ultimamente, com um aumento constante de uma ampla gama de novas práticas participativas, em sua maioria oriundas do engajamento institucional local na experimentação de inovações democráticas formalizadas, mas também com processos de rejuvenescimento do ativismo crítico urbano. Ambas são mudanças importantes em um país onde a crise econômica afetou profundamente a satisfação com a política representativa, ${ }^{14} \mathrm{e}$ onde, apesar de sua Constituição enfatizar a importância da promoção da democracia participativa (art. 2), no passado não houve tentativas reais de moldar o Estado ao redor de objetivos de envolvimento direto dos cidadãos na construção de políticas públicas e da gestão financeira e territorial.

Conscientes da dificuldade de provar as relações de causa e efeito na incidência mútua de fenômenos tão complexos e articulados, neste ensaio vamos tentar afunilar a nossa análise para temas mais ligados aos movimentos e aos fóruns urbanos e, particularmente, para o domínio das políticas de habitação, exemplo primordial da conjuntura de fraquezas na estruturação de políticas públicas estruturais e da forte onda de políticas austeritárias adotadas pelo Estado no período 2011-2015 (incluindo, também, as tensões com outras tendências em diferentes escalas e níveis institucionais).

Na próxima secção, analisar-se-á, justamente, como às políticas nacionais sustentadas quase exclusivamente no mercado e dirigidas principalmente para a recuperação econômica do setor imobiliário e da construção 
civil, formaram-se em paralelo com cortes nos investimentos públicos em habitação. De tal forma, afetaram-se os territórios locais, e transformaram-se profundamente, em poucos anos, tecidos urbanos como o da Região Metropolitana de Lisboa. Essa segunda parte do texto procurará seguidamente mostrar como o tecido social tem começado a reagir a essas transformações.

Em tal perspetiva, e complementarmente à reflexão proposta por Allegretti (2018) sobre processos participativos "por convite", desenvolvidos em Portugal na última década (muitas vezes com objetivos e volumes de recursos limitados) pelos municípios (Blas e Ibarra, 2006), o presente texto concentrar-se-á nos movimentos urbanos de nova geração. Especificamente, o texto tratará, sobretudo, de movimentos provindos dessas causas, gerados por dinâmicas de "participação por irrupção" (ibid.), que tem vindo a forjar práticas de autoafirmação, de resistência ou mesmo de dissidência, inspiradas em imaginários urbanos alternativos (cf. Subirats apud Coletivo Política en Red, 2007, p. 54).

\section{Continuidades e transformações: notas sobre o sistema de habitação português}

Em dezembro de 2016, a Relatora Especial da ONU pela Habitação Adequada visitou Portugal. 0 relatório da sua visita (Fahra, 2017) mostrou que Portugal está a atravessar uma profunda crise da habitação, crise caraterizada por uma dupla natureza: por um lado, a permanência de formas de habitação precária - pelo menos 25 mil famílias vivem em tais condições (IHRU, 2018) - e de habitação pública em péssimas condições; por outro, a crescente pressão sobre faixas sempre mais amplas da população, e especialmente inquilinos de classes baixas e médias, causada pelo rápido crescimento do custo da habitação que se tem verificado nos últimos anos.

Para melhor compreender essa conjuntura, é útil caraterizar rapidamente o sistema de habitação típico de Portugal. Como os outros países do Sul da Europa (Allen et al., 2004), Portugal é caraterizado pela prevalência da habitação própria: três em cada quatro famílias vivem em casa de propriedade. Esse sistema resulta da adesão substancialmente unânime ao ideal da habitação de propriedade como instrumento de estabilidade social. Se, nos anos da ditadura (1926-1974), o discurso sobre Portugal como país de proprietários era central à retórica do Estado Novo, as coisas pouco mudaram com a democracia: os subsídios aos empréstimos para compra de habitação, formalmente concluídos em 2002, mas ainda a componente mais cara da despesa pública com habitação, terão sido a "política" de habitação mais importante e estável desde os anos 1980. Não surpreende, portanto, que o setor do arrendamento tenha caído de 46\% em 1970 para 20\% em 2011 (Fahra, 2017, p. 7). Por seu lado, a habitação pública representa menos de $3 \%$ do parque habitacional.

0 mercado do arrendamento e a habitação pública encontram-se concentrados nas grandes cidades, principalmente Lisboa e Porto. Assim, a estabilidade habitacional proporcionada pela propriedade - no sistema português, sem dúvida, a forma mais estável de 
habitação - é menos prevalente exatamente nos contextos em que as transformações que descreveremos a seguir foram mais intensas. $\mathrm{Na}$ verdade, o estoque habitacional relacionado com o mercado do arrendamento, e sobremaneira com a crise financeira que colocou o endividamento (público e privado) em níveis insustentáveis, tornou-se o enfoque central das reformas no sector imobiliário aprovadas durante os anos da austeridade. 0 memorando de entendimento assinado entre Portugal e as instituições financiadoras externas exigia de forma explícita a liberalização do mercado de arrendamento (EC, 2011, p. 87). 0 governo de então respondeu com o Novo Regime de Arrendamento Urbano (NRAU; lei n. 31/2012) que reduziu as amplas proteções dos inquilinos, facilitou os despejos em caso de obras e transformou habitações em alojamentos turísticos (Alojamento Local). 0 objetivo do NRAU, em suma, era de acabar com os contratos existentes de renda controlada, resultantes dos "congelamentos" de rendas aplicados nas décadas anteriores. Esses congelamentos, num contexto nacional no qual o suporte ao arrendamento nunca foi prioritário, terão sido a única política direcionada aos inquilinos nos mercados não sociais, em contextos políticos e económicos obviamente cheios de contradições. Com o tempo, os congelamentos das rendas criaram situações altamente paradoxais, com inquilinos a pagar valores extremamente reduzidos (ainda existem contratos de poucas dezenas de euros mensais) sem qualquer compensação aos proprietários. Os congelamentos das rendas têm sido apontados, por muitos, como a razão principal da progressiva degradação do património edificado nos centros urbanos portugueses. Uma narrativa crescentemente sólida e, por sua vez, incrementalmente agressiva, criando-se, assim, uma ampla justificação para as políticas de liberalização do mercado de arrendamento. De uma outra perspetiva, é também possível interpretar os congelamentos de rendas antigas como uma componente de estratégia mais ampla que terá fomentado, a partir dos anos 1970/1980, uma acumulação de capital para a suburbanização territorial estratégia complementada, justamente, através dos subsídios para a aquisição de habitação.

Essa breve descrição mostra como o sistema português de habitação se tem caracterizado por sérios desequilíbrios históricos - desequilíbrios que, afinal, foram em algumas partes mitigados, mas, em outras, acentuados com as políticas austeritárias. Assim, consideramos que uma reflexão rigorosa sobre esses temas tenha que partir da compreensão das necessidades de reforma das políticas que, afinal, moldaram esses desequilíbrios. Veremos a seguir como a conjuntura das transformações socioeconómicas e as novas pressões sociais e económicas têm paulatinamente despoletado uma potencial nova era nas respectivas agendas políticas. De facto, entre os programas de intervenção pública, a proposta de uma Lei de Bases de Habitação e outros diplomas em discussão sobre temas relacionados (alojamento local, descentralização administrativa), podemos talvez vislumbrar uma perspetiva de transformação do "sistema" de habitação português. Será essa nova leva de políticas - fruto de uma sua discussão crítica, embora em movimento - o último objeto de discussão deste ensaio. Para chegar a essa discussão, será necessário descrever as condições que levaram a habitação para o centro das agendas políticas, começando pelas transformações em curso em Lisboa. 


\section{Lisboa e o seu novo mainstream metropolitano}

Lisboa é uma cidade que, nos últimos anos, tem se distinguido por um ritmo muito acelerado de mudança; sendo particularmente visíveis, neste período quase vertiginoso, as diferenças e os conflitos - mas também as ambivalências - entre os elementos de inovação e de transformação e os de fomento de novos tipos de desigualdade e de segregação. Ao nos aproximarmos do final desta segunda década do século XXI, a capital portuguesa emerge como cada vez mais cosmopolita e integrada nas tendências globais de vanguarda (Seixas, Magalhães e Costa, 2013; Costa et al., 2017; Rossi e Tulumello, 2018).

A cidade tem procurado forjar novas perspetivas para a qualidade de vida urbana, assim como para o empreendedorismo, alterando de forma paradigmática suas políticas e investimentos - em espaços públicos, infraestruturas e serviços ambientais, bem como nas suas próprias estruturas de governação territorial. De facto, a cidade reformulou de forma bastante radical suas estruturas políticas e administrativas nos níveis mais próximos dos cidadãos, no nível das suas freguesias, ${ }^{15}$ preparando-se, por sua vez agora, para uma nova vaga de reforço dos seus poderes e recursos graças a um processo de acrescida descentralização do Estado central, em que se prevê uma alteração relativamente importante do status quo da administração territorial portuguesa nos próximos anos.

Essa evolução, que reflete uma atitude significativa e deliberada de transformação, tem resultado no fomento de um governo urbano com maiores competências e responsabilidades, assim se constituindo uma série de novas dinâmicas sociais e políticas; consideravelmente perturbadoras para a cultura de um Estado com profundas tradições centralistas. No entanto, é também em Lisboa que se mantém um difícil legado político e cultural que durante décadas desconsiderou os valores da vida urbana. E onde, hoje, estão a ser estabelecidos novos padrões de desigualdade e de segregação socioespacial, em particular no acesso às necessidades básicas, tais como a habitação. Por conseguinte, e apesar das tendências de inovação política, determinadas incertezas permanecem, em face das novas necessidades versus capacidades de governação urbana, em face da redistribuição dos recursos e capitais da nova economia e em face da defesa dos bens comuns e dos direitos fundamentais na cidade.

Este texto vai, nos pontos seguintes, procurar traçar esses padrões, com referência particular ao sistema habitacional, a partir da dinâmica crise/pós-crise, entre o início desta década e os tempos presentes.

Quando Portugal recebeu o seu resgate financeiro em 2011, a cidade de Lisboa unidade administrativa central de uma área metropolitana com quase 3 milhões de habitantes - tinha 552.700 habitantes e 322.865 unidades habitacionais, das quais 50.289 estavam vagas (Minder, 2018) e quase $5.000 \mathrm{em}$ condições de abandono (Figura 1). No final de 2014, Lisboa e a sua região metropolitana estavam a sofrer os mais pesados impactos da crise económica nacional e das políticas de austeridade (Seixas et al., 2015). 
Figura 1 - Habitações degradadas/abandonadas em Lisboa, a partir de 2009, por tipologia do proprietário

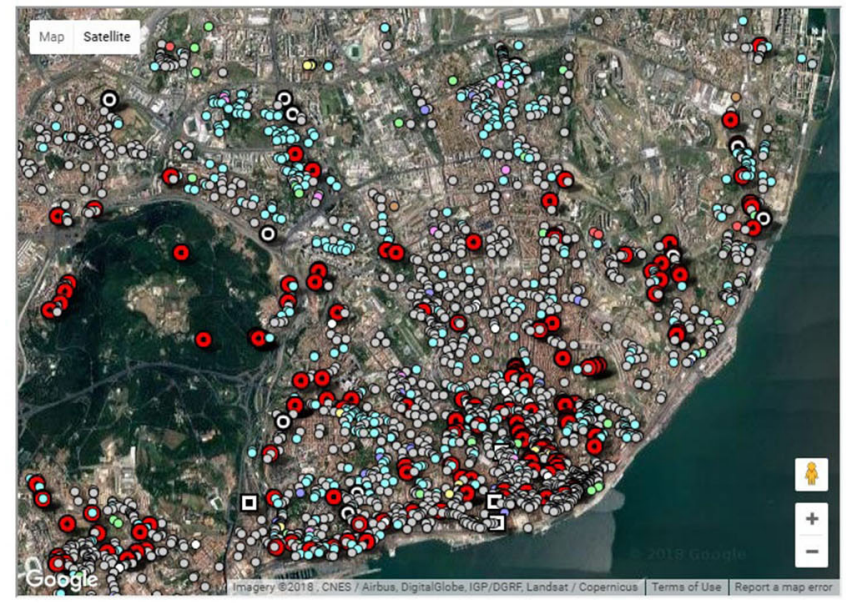

O - Private property (3155)

○ - No information available (922)

- Municipality (314)

- - Santa Casa da Misericórdia (63)

○ - State and state entities (60)

○ - Other no-profits (49)

○ - EPUL (municipal enterprise) (42)

$\odot$ - Partially owned by the municipality (26)

O - Other entities (24)

○ - Mixed property (15)

口 - Public enterprise (11)

- - Housing co-op (8)

Fonte: Tretas.org (https://tretas.org/PrediosDevolutosLisboa\#Localiza.2BAOcA4w-o_dos_Pr.2BAOk-dios_Devolutos). Baseado em dados da Câmara Municipal de Lisboa.

No entanto, vários processos, iniciados em 2009, abriram caminho para a recuperação econômica e as transformações no sistema habitacional da cidade. 0 turismo começou a crescer em 2009, em parte devido a investimentos e campanhas publicitárias de promoção por parte do governo local (ibid.) e, em parte, pelo apoio prestado por várias revistas globais de tendência, à procura de um valente substituto depois da queda do turismo nos países do norte da África causada pelas turbulências políticas e o terrorismo global. A tendência fortaleceu-se entre 2016 e 2017, quando Lisboa ganhou vários reconhecimentos (como os do World Best Citybreak e World Best Cruise Harbor), que acabaram entrando na conta do notável sucesso de Portugal nas últimas edições dos World Travel Awards. ${ }^{16} 0$ boom turístico foi acompanhado por novas tendências. Por um lado, a cidade conseguiu tornar-se atraente para startups e jovens profissionais (ver Rossi e Tulumello, 2018), aposentados (atraídos por incentivos fiscais para "residentes não habituais" introduzidos nos anos da crise $)^{17}$ e, cada vez mais, estudantes estrangeiros. ${ }^{18}$ Por outro lado, Lisboa tornou-se atrativa para os investimentos internacionais no sector imobiliário, em parte devido ao esquema Golden Visa. Este último concede acesso ao mercado europeu e ao espaço Schengen para investimentos imobiliários a partir de $500.000 €_{,}{ }^{19}$ em parte devido ao crescimento do mercado imobiliário e, consequentemente, dos elevados retornos dos investimentos (ver Introdução). Sem surpresa, o rápido influxo de indivíduos com maior capacidade de compra e o peso dos investimentos 
Figura 2 - Alojamentos disponíveis no AirBnB em Lisboa,

a partir de maio de 2018

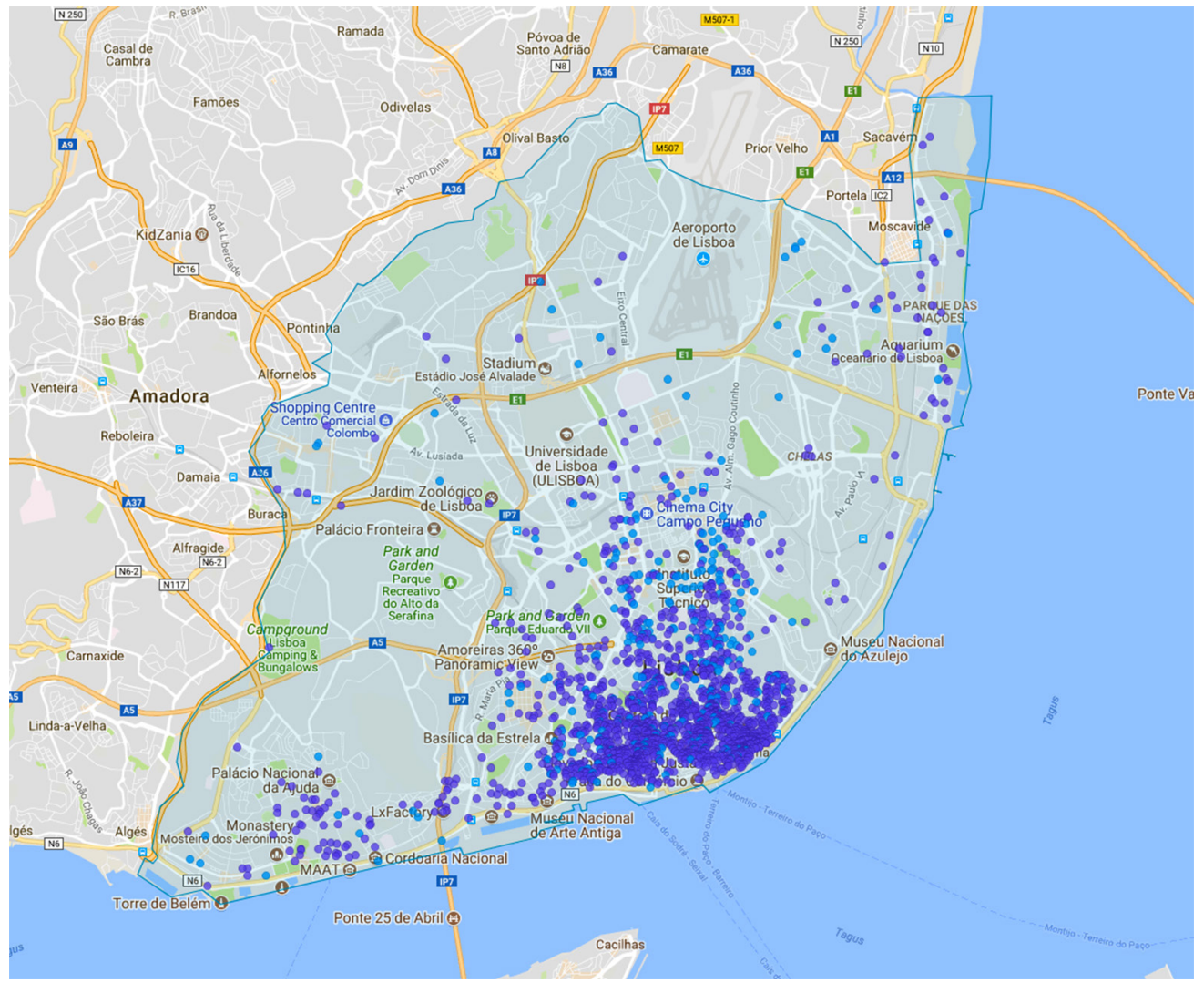

Fonte: AirDNA (reprodução autorizada por cortesia de AirDNA). Ver: www.airdna.co.

internacionais produziram um impressionante crescimento dos preços de imóveis, com aumentos anuais de dois dígitos na maioria dos municípios da Região Metropolitana de Lisboa (ver Introdução). De facto, no seu último relatório sobre a estabilidade financeira, até o Banco de Portugal sublinhou o papel do investimento estrangeiro no crescimento dos preços da habitação, bem como alertou para a possibilidade de uma explosão da bolha especulativa (Banco de Portugal, 2018).
É importante, no entanto, destacar um conjunto de tensões subjacentes às recentes transformações. Sem dúvida, o crescimento da indústria do turismo com dois dígitos anuais tem sido um componente crucial da recuperação econômica do país, impulsionando a reforma do patrimônio arquitetónico. Ele é considerado, por muitos portugueses, como um fenómeno "win-win", na medida em que também é visto como um dos fatores centrais da caída da taxa de desemprego (que passou de 
um pico de cerca de 17\% em 2013 para 8\% do início de 2018), embora sem considerar que 0 emprego no setores do turismo e do imobiliário é muitas vezes precário, malpago e marcado pela alta rotatividade dos funcionários (ver Teles, 2018). Ainda assim, instituições locais e nacionais parecem ter vindo a empurrar o tecido econômico para o turismo, sobretudo na ausência de uma estratégia global e de direções alternativas de desenvolvimento.

Essa realidade, juntamente com o fracasso sistemático da redistribuição do valor económico agregado gerado pelo turismo, tem tido consequências muito sérias e de tempos longos. Ainda que, em 2016 - pela primeira vez em décadas -, Lisboa não tenha vindo a perder habitantes em comparação com o ano anterior, este não foi o caso dos jovens adultos (com idades compreendidas entre os $20 \mathrm{e}$ os 34 anos), que diminuíram cerca de $30 \%$ no período 2011-2016. ${ }^{20} 0$ envelhecimento é uma questão antiga da população portuguesa, pelos seus padrões europeus e migratórios, mas existem evidências de que a falta de habitação a preços acessíveis tem desempenhado um papel nessa perda (Costa, 2017), gerando um fluxo de residentes para o anel suburbano norte e para a margem sul do rio Tejo. De fato, um estudo recente da Caritas enfatizou como o acesso à moradia é problemático para as gerações jovens (Caritas Portuguesa, Caritas Europa, 2017).

A elaboração de correlações causais rigorosas entre as tendências imobiliárias e as expulsões do centro da cidade não é simples. Por exemplo, alguns grupos de jovens adultos podem ter conseguido comprar casas a custos mais baixos durante a crise e podem agora alugá-las ou revendê-las com valores mais altos, mudando-se para municípios periféricos, onde podem pagar por casas maiores e altos padrões de qualidade de vida. Ainda assim, há um número crescente de casos - por exemplo, aqueles reportados a grupos ativistas locais como "Habita" (ver abaixo) e "Stop Despejos", de pessoas que foram despejadas e não tiveram outra escolha a não ser se mudar para fora da cidade de Lisboa. ${ }^{21}$ Isto pode sinalizar mais um fenómeno, isto é, uma nova ronda de gentrificação nos bairros periféricos de Lisboa e nos seus arredores imediatos, devido ao reassentamento de jovens adultos ativos com altas qualificações e salários relativamente elevados. ${ }^{22}$

Vale aqui a pena realçar que um dos maiores retos do próximo futuro reside na construção de banco de dados estatísticos rigorosos e geograficamente detalhados sobre 0 mercado habitacional, para além daqueles que são disponibilizados apenas a cada 10 anos por meio de censos (os quais são, obviamente, incapazes de captar as transformações turbulentas dos últimos anos). 0 fato é que a maioria dos dados atualizados é daqueles fornecidos por empresas e consultores imobiliários, cujos interesses em omitir alguns fenómenos ou em representar o mercado com crescimento e dinamismo mais rápidos do que na realidade acabam sendo um risco que pode afetar as próprias análises das tendências e requer uma séria contraestratégia pública, assim como um forte empenho da sociedade civil. 


\section{Os novos movimentos urbanos e a construção de contranarrativas}

Não será surpreendente que as realidades descritas nos pontos anteriores, decorrentes quer da ampla crise económico-financeira e também política, quer dos novos dilemas provocados pelas propostas de recuperação económica, acarretam profundas contradições. Essas contradições, crescentemente evidentes, a par da relativa debilidade nas respostas políticas em áreas vitais de direitos urbanos, tais como a habitação, têm sido um terreno fértil para o posicionamento de uma nova geração de movimentos sociais e urbanos, de base local, mas muito interligados em redes digitais e com crescentes interligações globais. Movimentos e redes que, numa interação com fronteiras ténues entre si e vocalizando novas expressões e reivindicações de cidadania por bens considerados comuns (Mattei, 2011; Nel.lo, 2015) e por diversas formas, estruturas e assunções, detêm uma evidente heterogeneidade. Não obstante, a maioria desses movimentos mostra ter em comum a defesa do direito à habitação e, de forma crescentemente reconhecível, do direito à cidade, nas suas narrativas e exigências.

Esses movimentos urbanos, embora ainda relativamente marginais na vida sociopolítica da cidade de Lisboa - quando comparados, por exemplo, com os seus congéneres nas maiores cidades espanholas -, encontram-se em evidente crescimento de base sociocultural e também mediática. Eles surgem por formas relativamente genéricas de consciência cívica e para determinados temas transversais ou são de ordem mais específica e perante determinadas temáticas ou campos de reivindicação. Verificam-se, por sua vez, no principal centro urbano da metrópole, mas também nas vastas periferias da cidade e, sem dúvida, alicerçam-se por ampla utilização das redes digitais.

A Tabela 1 apresenta uma listagem sistematizada dos mais recentes movimentos cívicos urbanos em Lisboa, incluindo uma tipologização que apresenta graus de sucesso e tendências próximas de evolução. A larga maioria desses movimentos encontra-se em condição de estabilidade ou mesmo de fortalecimento, 0 que mostra uma tendência de crescente posicionamento dos movimentos urbanos na vida política da cidade - e, também, a continuidade (ou mesmo o acentuar) das pressões sobre as quais estes se mobilizam.

A dimensão mais crítica na recente mobilização da população, e no recrudescimento dos protestos por parte dos movimentos urbanos, encontra-se sem margem para dúvidas nas dimensões do mercado imobiliário e habitacional da cidade. As associações locais e os movimentos urbanos da cidade, das mais variadas índoles, pressionam cada vez mais vincadamente - com argumentos de base material e imaterial - contra 0 aumento das rendas, a especulação imobiliária e o consequente esvaecimento da vida quotidiana de múltiplos bairros da cidade. Nesse sentido, diversas associações e movimentos informais da cidade juntaram-se, criando um movimento de largo espectro, intitulado "Movimento Morar em Lisboa", ${ }^{23}$ que apresentou uma carta pública em fevereiro de 2017. Esse movimento tem sido um fórum aberto de apresentação de propostas aos diversos responsáveis políticos e institucionais pela habitação na cidade. 
Tabela 1 - Recentes movimentos cívicos urbanos em Lisboa

\begin{tabular}{|c|c|c|c|c|c|}
\hline $\begin{array}{c}\text { Área de } \\
\text { intervenção }\end{array}$ & Forma & Territórios & $\begin{array}{c}\text { Tipo de } \\
\text { reivindicação }\end{array}$ & Grau de sucesso & Tendência \\
\hline Habitação & $\begin{array}{l}\text { Diversos movimentos } \\
\text { e associações }\end{array}$ & $\begin{array}{l}\text { Sobretudo centro de } \\
\text { Lisboa, estendem-se } \\
\text { às áreas suburbanas } \\
\text { em temas do } \\
\text { realojamento }\end{array}$ & $\begin{array}{l}\text { Direito à habitação/ } \\
\text { rendas apoiadas } \\
\text { versus liberalização } \\
\text { do Mercado } \\
\text { imobiliário, } \\
\text { gentrificação turística, } \\
\text { realojamento }\end{array}$ & $\begin{array}{l}\text { Crescente atenção } \\
\text { social e mediática } \\
\text { para as questões da } \\
\text { habitação; crescente } \\
\text { pressão política; } \\
\text { crescente percepção } \\
\text { e mobilização social }\end{array}$ & Em fortalecimento \\
\hline Ecologia & $\begin{array}{l}\text { Movimentos } \\
\text { colectivos e } \\
\text { comunitários muito } \\
\text { variados }\end{array}$ & $\begin{array}{l}\text { Centro de Lisboa, } \\
\text { Bairros sociais }\end{array}$ & $\begin{array}{l}\text { Horticultura urbana } \\
\text { comunitária e } \\
\text { orgânica }\end{array}$ & $\begin{array}{l}\text { Projectos vitoriosos } \\
\text { em Orçamentos } \\
\text { Participativos, } \\
\text { terrenos e edifícios } \\
\text { ocupados, crescente } \\
\text { percepção social }\end{array}$ & Estável \\
\hline Mobilidade & $\begin{array}{l}\text { Diversos movimentos } \\
\text { e associações }\end{array}$ & $\begin{array}{l}\text { Sobretudo centro de } \\
\text { Lisboa }\end{array}$ & $\begin{array}{l}\text { Direito à mobilidade } \\
\text { não motorizada na } \\
\text { cidade }\end{array}$ & $\begin{array}{l}\text { Relativo sucesso no } \\
\text { lobbying político, } \\
\text { crescente perceção } \\
\text { social }\end{array}$ & Estável \\
\hline $\begin{array}{l}\text { Desenvolvimento } \\
\text { Comunitário }\end{array}$ & $\begin{array}{l}\text { Movimentos } \\
\text { colectivos e } \\
\text { comunitários muito } \\
\text { variados }\end{array}$ & $\begin{array}{l}\text { Variados bairros por } \\
\text { toda a metrópole }\end{array}$ & $\begin{array}{l}\text { Centros sociais, } \\
\text { apoio e providência } \\
\text { social, identidade } \\
\text { e representação } \\
\text { cultural em bairros } \\
\text { sociais e minorias }\end{array}$ & $\begin{array}{l}\text { Consolidação de } \\
\text { centros comunitários; } \\
\text { aumento gradual } \\
\text { de actividades } \\
\text { socioculturais; } \\
\text { crescente pressão } \\
\text { política para os } \\
\text { temas; fomento de } \\
\text { programas municipais }\end{array}$ & $\begin{array}{l}\text { Estável ou em } \\
\text { fortalecimento }\end{array}$ \\
\hline Feminismo & $\begin{array}{l}\text { Movimentos } \\
\text { e associações } \\
\text { específicas }\end{array}$ & $\begin{array}{l}\text { Sobretudo âmbito } \\
\text { nacional }\end{array}$ & $\begin{array}{l}\text { Igualdade de } \\
\text { género e combate à } \\
\text { discriminação racial }\end{array}$ & $\begin{array}{l}\text { Atenção mediática; } \\
\text { aumento de } \\
\text { iniciativas e debates } \\
\text { nos territórios }\end{array}$ & Em fortalecimento \\
\hline Antirracismo & $\begin{array}{l}\text { Movimentos } \\
\text { e associações } \\
\text { específicas }\end{array}$ & $\begin{array}{l}\text { Âmbito nacional } \\
\text { bem como zonas } \\
\text { suburbanas da } \\
\text { metrópole }\end{array}$ & $\begin{array}{l}\text { Combate ao racismo } \\
\text { e à discriminação } \\
\text { socioterritorial }\end{array}$ & $\begin{array}{l}\text { Carta de denúncia de } \\
\text { racismo em Portugal } \\
\text { à ONU; adopção de } \\
\text { dados étnicos para os } \\
\text { Censos } 2021\end{array}$ & $\begin{array}{l}\text { Estável ou em } \\
\text { fortalecimento }\end{array}$ \\
\hline
\end{tabular}

Fonte: Seixas e Guterres (2018).

Um dos locais da cidade com maior dinâmica cívica e de acção por parte dos movimentos urbanos situa-se no eixo da avenida Almirante Reis e nos seus diversos bairros envolventes. Com a saturação imobiliária e turística do núcleo mais histórico da cidade, esse eixo tem sido receptor de novas vocações residenciais, sobretudo por jovens adultos, estudantes nacionais e estrangeiros, recém-licenciados; mas também outros moradores empurrados para essas zonas ainda relativamente acessíveis em termos de rendas, pela saturação de 
algumas outras áreas da cidade que tradicionalmente os abrigavam (Malheiros Carvalho e Mendes, 2013). Nesses bairros, embora ainda se mantendo como territórios muito tradicionais de Lisboa, têm-se crescentemente assistido a estilos de vida mais comunais e de partiIha de apartamentos; provocado pelos baixos salários das novas gerações de licenciados, precariedade laboral; mas também pela adopção voluntária a novas formas de vida na cidade e ao fortalecimento de redes associativas. Dois casos recentes, com resultados aparentemente distintos, ilustram bem os conflitos de nova ordem nessas áreas, bem como seus potenciais resultados, dadas as forças e narrativas em presente posicionamento: o jardim do Caracol da Penha e a ocupação do edifício municipal da rua Marques da Silva.

0 primeiro caso refere-se a um espaço baldio e expectante, de propriedade municipal, numa zona densamente urbanizada. Perante a pretensão do município de construir um parque de estacionamento, um grupo de moradores locais iniciou um movimento durante 0 ano de 2016 para a criação de um jardim público. ${ }^{24} 0$ movimento, sustentado por uma forte mobilização local, técnica e mediática - e que chegou a vencer o orçamento participativo institucionalizado pelo próprio município -, conseguiu levar avante a sua reivindicação; embora presentemente teve que estruturar as suas reivindicações iniciais com as estratégias e, sobretudo, com a cultura administrativa, mais próprias do município.

0 segundo caso refere-se a uma ocupação por um grupo de ativistas de um edifício municipal devoluto - bem perto do espaço expectante do primeiro caso. A ocupação, desencadeada em plena campanha eleitoral autárquica em setembro de 2017, exigia um debate mais crítico em torno da especulação imobiliária da cidade, do enorme aumento das rendas e das débeis políticas de habitação do município. Um grupo de "okupas" organizou-se coletivamente por forma a realizar obras de reforma e transformar o prédio num espaço comum, com uma cozinha comunitária, uma sala de estudo e salas de reuniões. Até ao seu desalojamento quatro meses depois, os "okupas" prepararam, através de uma "Assembleia do Comum", uma proposta de "Programa Quota de Habitação Comum" 25 para cidadãos em situação de carência habitacional. Apesar do desalojamento, estão presentemente abertos os canais de negociação entre os ativistas e o município, que considerou o programa como base plausível para debate. Por seu lado, a Assembleia e seus grupos de trabalho temáticos mantêm-se ativos, sendo diversas actividades progressivamente integradas noutro grupo informal intitulado "Vizinhos de Arroios", que vem organizando debates semanais quase sempre lotados. Tais iniciativas têm vindo a cooperar numa rede de espaços de apoio para atividades públicas, incluindo espaços de pensamento radical, tais como as associações Crew Hassan e a RDA69, bem como outros espaços culturais igualmente empenhados na conscientização dos direitos urbanos em Lisboa; o que demonstra a estruturação de uma rede de movimentos.

Efetivamente, primeiro nos bairros envolventes a essas zonas da cidade, mas de forma crescente para outros bairros, têm surgido espaços e iniciativas que corroboram essas novas formas de expressão. De 2008 a 2016, esses tipos de espaços coletivos mais do que duplicaram (Costa et al., 2017), com crescentes repercussões na vivência da cidade, mas 
também nas suas percepções políticas. São múltiplos os exemplos, dos quais se poderão destacar os seguintes: a) a programação cultural no espaço Terraço ${ }^{26}$ num edifício ocupado comunalmente; b) o apoio alargado à Horta do Monte e a criação da horta da rua das Barracas numa socialização entre ativistas e a população local, privilegiando a cultura orgânica e a permacultura; c) as atividades do Centro Social RDA 69 com debates, ciclos de cinema, refeitório popular e biblioteca; d) a Cicloficina dos Anjos, que arranja bicicletas através de voluntários que ensinam os utilizadores nas práticas mecânicas; e) a Cooperativa Zona Franca, no bairro das Colónias, com uma cantina popular, tertúlias, lançamentos de livros, etc.

É de referir que o considerável incremento da atividade cívica nesses territórios, bastante centrais em face da geografia metropolitana de Lisboa, não se deve apenas à ação desses grupos de base. Na verdade, decorreu de um deliberado e estratégico investimento municipal em toda a zona. Confirma-se, assim, que a combinação entre investimento público de base municipal e iniciativas de base local pode funcionar numa perspectiva de mútuo fomento. Mas também, e de forma relativamente esperada, como fonte de novos tipos de discordâncias e de conflitos de base política. Sobretudo perante os resultados da conjugação de relevantes investimentos públicos com uma abertura claramente liberal aos investimentos financeiros externos; provocando acentuados efeitos de gentrificação.

É igualmente relevante recordar que os movimentos de cidadania não se resumem à cidade mais histórica. Existem, nomeadamente, múltiplos bairros sociais no seu sistema urbano e que constituem cerca de um sétimo ${ }^{27}$ da população da cidade; emergindo, por sua vez, nesses territórios uma nova geração de movimentos urbanos. Ao contrário das associações surgidas após a revolução de 1974, e sobretudo dedicadas ao direito à habitação, a nova geração de associações preocupa-se mais com as questões do habitat e com o sufrágio dos diversos direitos constitucionais; em questões como a representatividade política (em especial nos bairros onde habitam descendentes de imigrantes); os direitos das mulheres e das crianças; a qualidade dos equipamentos e dos espaços públicos; os transportes públicos e a própria integração na vida urbana. Por seu lado, os movimentos que partem das periferias - sociais e geográficas - da cidade também se agregam em rede e vão para além da dimensão de "bairro". De acordo com Costa et al. (ibid., pp. 204-208), a espacialização dessas formas de expressão, sobretudo de índole cultural, difere consideravelmente das dos movimentos do centro urbano, sendo aqui desenvolvidas em espaços de esferas mais privadas, mas que abrigam espaços de trabalho em rede e com actividades comuns.

Esta breve discussão tem mostrado como as rápidas transformações em curso em Lisboa foram acompanhadas pela emergência de novas redes preocupadas com habitação e além dessa. Mais em geral, essa nova onda de ativismo apostou em três estratégias principais: 1) organizar ações com diferente cariz, mas sempre capazes de atrair cobertura da comunicação social; 2) dialogar com os atores políticos recentemente eleitos, aproveitando, em certas ocasiões, também da proximidade de alguns políticos com os próprios movimentos; e 3) produzir conhecimento através de práticas de investigação-ação e, assim, 
fortalecer o diálogo entre ativistas e instituições académicas.

Esta última linha é evidente no retorno da habitação no centro dos estudos urbanos, e especialmente por obra de novas gerações de investigadores. Por exemplo, o recém-criado "Urban Transitions Hub", do Instituto de Ciências Sociais da Universidade de Lisboa, recebeu financiamento por três projetos da Fundação Nacional para a Ciência e Tecnologia, ${ }^{28}$ organizou dois Fóruns da Habitação ${ }^{29}$ e criou redes com grupos ativistas, incluindo Habita, associação ativa desde os meados dos anos 2000, e com muitas redes nacionais e internacionais. Outros grupos académicos nessa área foram o Gestual (Universidade de Lisboa), o Cics.Nova (Universidade Nova de Lisboa) e o Dinâmia/CET (Instituto Universitário de Lisboa), que uniram forças na criação do grupo Urbanologista; o Centro de Estudos Sociais da Universidade de Coimbra (que valoriza a produção de dados no seu "Observatório de Crises e Alternativas"); e o LAHB (Laboratório de Habitação Básica Participativa de Porto). ${ }^{30}$

Os novos atores têm vindo a colaborar com atores de longa data e, especialmente, nas tentativas de construir um "conhecimento ausente" sobre as interações entre habitação e outros campos de ação. Nesse campo, a ação da associação Habita foi crucial. Ela tem estado na origem de campanhas importantes, como \#QueremosOrçamento (denúncia do insuficiente orçamente dedicado à habitação), a "Caravana pelo Direito à Habitação" (que tem vindo a percorrer o país para recolher informação sobre o estado da habitação precária) e no nascimento da plataforma Stop Despejos (grupo de ação direta contra os despejos). ${ }^{31}$
Um dos aspectos mais importantes visíveis na panóplia de iniciativas ativistas e políticas - apesar da abordagem radical de algumas delas - tem sido uma crescente capacidade de abrir e manter o diálogo com as autoridades políticas, por meio de conversas diretas e da participação em eventos e debates públicos, assim como também em formas cada vez mais profissionalizadas de tentativa de influência na formação de políticas públicas.

\section{Aberturas, ausências, contradições: o campo das políticas}

0 efeito mais evidente da multiplicação de redes e de atores crescentemente interventivos em torno das questões do direito à habitação em Lisboa terá sido seguramente o posicionamento do tema no centro do debate político. Embora esse posicionamento tenha rariz global nas causas e, sobretudo, nas consequências da crise económica global desencadeada desde 2008 (Madden e Marcuse, 2016), em Portugal podemos observar algum lapso temporal - e percepcional - a esse respeito. De facto, em muitos países, as relações entre as causas e as consequências da crise foram sentidas de forma muito vincada com as pressões habitacionais, tendo levado à criação de importantes reações sociais e políticas e, desde logo, a novos movimentos sociais - sendo 0 caso mais evidente a "Plataforma de Afectados por la Hipoteca" em Espanha. ${ }^{32}$ Em Portugal, essas tendências sucederam-se, sobretudo, alguns anos após a eclosão da crise e 
perante os primeiros resultados das propostas de retomada económica.

Esse desfasamento incita a uma necessária interpretação mais específica, não somente das suas razões, mas também sobre as formas mais específicas de como as novas pressões sociais que finalmente se instalam nos anos mais recentes estarão a ser transmitidas ou assimiladas para os campos da política - e das políticas, em termos mais concretos. Podemos identificar três momentos cruciais, a esse respeito.

0 primeiro momento coincide com os resultados das eleições nacionais de 2015 e com a formação do novo governo socialista e a sua maioria de centro-esquerda na Assembleia da República, como acima já mencionado. Não obstante, nessa primeira fase, o novo governo ignorou em considerável medida o tema da habitação, priorizando, sobremaneira, as reivindicações centrais dos sindicatos bem como determinadas formas de política económica de carácter neokeynesiano - através do estímulo na procura interna por via de cortes nos impostos e de retomada dos salários dos funcionários públicos. Entretanto, começava a ser por demais evidente quer o fortíssimo impulso do mercado turístico nacional priorizava o aquecimento dos mercados imobiliários nos territórios mais centrais e simbólicos do país. Assim, um segundo momento de transição sucede-se no verão de 2017 - no rescaldo da publicação do relatório da ONU pelo Direito à Habitação Adequada (ver secção "Continuidades e transformações: notas sobre o sistema de habitação português") e enquanto cresciam as pressões sociais. Nesse período, o governo assumiu finalmente a habitação como "prioridade política" (Lusa, 2017). 0 Primeiro Ministro António Costa menciou explicitamente os riscos de exclusão das novas gerações, especialmente dependentes de um mercado de arrendamento em explosão de preços (Tiago, 2017). 0 ato central dessa nova fase política coloca-se na criação da Secretaria de Estado da Habitação em julho de 2017. Assume o cargo uma perita em regeneração urbana e imobiliária ${ }^{33}$ que tem demonstrado interesse e capacidade para abrir debate com a sociedade civil, sendo o número de encontros organizados nos primeiros meses do seu encargo sem dúvida significativo. Essa atitude da nova Secretária de Estado demonstrou, pelo menos, um reconhecimento da complexidade dos agentes e dos problemas em questão e a evidente necessidade de uma melhor articulação entre os níveis nacional e local; bem como entre agentes públicos, privados e associativos. Porém, não deixa de ser uma Secretaria de Estado num governo sobremaneira preocupado em conseguir transmitir a mensagem - em nível nacional, mas também Europeu - de que as políticas de austeridade poderiam ser alteradas sem colocar em causa a consolidação orçamental e financeira do país. Ou seja, a nova Secretaria de Estado da Habitação deteria, à partida, um relevante diferencial entre vontade para agir e uma real capacidade - desde logo política, mas também financeira - para o fazer.

Finalmente, o terceiro momento sucede-se com as eleições autárquicas de outubro de 2017, quando habitação se torna, de forma assumida, o tema principal do programa, da campanha e, por consequência, da futura gestão da Câmara Municipal de Lisboa. Nessas eleições, o Partido Socialista, que governava Lisboa há já uma década - em coligação com pequenos, mas relevantes movimentos de cidadãos -, ganha votos em practicamente todo o país, por efeito do clima positivo e 
relativamente pós-austeritário. Mas em Lisboa perde a maioria absoluta que detinha, formando, assim, uma coligação de maioria com o Bloco de Esquerda, numa dinâmica que dará mais visibilidade aos vereadores mais preocupados com a habitação. Porém, mantem-se, nos primeiros meses pós-eleições, sobretudo no nível nacional, uma considerável defasagem entre os níveis discursivos e operativos. Tal defasagem poderá ser compreendida através dos conceitos de abertura, de ausência e de contradição.

0 conceito de abertura, que utilizamos aqui para frisar uma nova atitude de possibilidade para reforma, não se aplica somente ao diálogo promovido pela nova Secretária de Estado. 0 último ano tem sido caraterizado pelo sistemático posicionamento de uma panóplia de propostas de novos instrumentos legislativos. 0 primeiro pacote, até a data parcialmente aprovado, constitui a chamada Nova Geração de Políticas de Habitação (NGPH). ${ }^{34}$

A NGPH pretende constituir-se como uma política holística, abrangendo várias dimensões e, principalmente, a promoção de soluções públicas para famílias em estado de grave precariedade habitacional e o estímulo ao arrendamento de longa duração - mais intervenções específicas para dar soluções urgentes em caso de calamidades naturais e para estimular a coesão territorial. Entretanto, a Assembleia da República encontra-se a trabalhar sobre uma proposta de Lei de Bases de Habitação, ${ }^{35}$ cujo objetivo declarado é de atuar de forma transversal e com base no princípio constitucional do direito à habitação (art. 65) através de provisões como a proteção de despejo em caso de primeira habitação, uma melhor definição da função social da habitação (que deveria simplificar, por exemplo, a expropriação de ha- bitações mantidas devolutas por longo tempo) e o estabelecimento de estratégias plurianuais nacionais pela habitação.

Em nível municipal, e voltando a Lisboa, a Câmara Municipal tem reconhecido especialmente a necessidade de fixar residentes. ${ }^{36}$ Consequentemente, a Câmara lançou um ambicioso Programa de Renda Acessível que envolve a realização de parcerias público-privadas para a construção de complexos de uso misto, em que se prevê realizar 7.000 unidades de habitação acessíveis em 15 lotes e até ao ano de 2021. Nesse programa, o município participa, sobretudo, através da cedência dos terrenos.

Nesse panorama, o conceito de ausência é, por sua vez, compreensível perante uma cultura político-administrativa que, em Portugal, nunca colocou o desenvolvimento das cidades e dos territórios, de forma explícita, como objeto central das suas políticas nacionais (Seixas e Marques, 2015). 0 próprio Primeiro Ministro, quando declarou a habitação uma nova prioridade (Lusa, 2017), confirmou não estar em causa a liberalização do mercado. Sucessivamente, a própria Secretária de Estado tem repetido que a regulamentação não é parte central da estratégia do governo nessa área. Como mencionamos acima, as reformas cruciais aprovadas durante os anos da austeridade não estão a ser modificadas ou revogadas na sua essência, e o mesmo se aplica a outros temas relevantes para a transformação do panorama habitacional. Ou seja, por agora não se prevê a revogação ou modificação das regulamentações referentes aos Vistos Gold bem como ao regime fiscal de Residentes Não Habituais; ambos centrais para as dinâmicas de financeirização globalizada da habitação (Marujo, 2018) ou a liberalização do sistema de ordenamento do território. 
As únicas excepções, que dizem respeito a mudanças até agora confirmadas, encontram-se em pequenas - mas não obstante altamente simbólicas - alterações ao Regime de Arrendamento Urbano, tais como a proteção dos despejos de pessoas com mais de 65 anos ou com deficiência (lei n. 30/2018). Também se legislou no sentido de dar às autarquias municipais a capacidade de pôr limites aos estabelecimentos turísticos. Ausente está, ainda, a informação detalhada sobre os investimentos previstos para as novas políticas aprovadas não complementadas com dotações orçamentais no Orçamento de Estado de 2019).

Nas perspetivas de interpretação por nós propostas em termos de "tempos longos", consideramos muito útil esse conceito de ausência, porque ajuda a interpretar melhor a interseção entre a ausência de uma robusta política de habitação desenvolvida nos anos anteriores (Tulumello et al., 2018) com as liberalizações "austeritárias" do sistema de ordenamento e a ausência de uma estratégia complexiva e mais integrada com as realidades socioterritoriais, sobretudo para os fundamentais setores do turismo e do imobiliário.

Como repetidamente denunciado por associações como a Habita (Silva, 2017), os novos programas governamentais, embora potencialmente capazes de resolver algumas situações específicas, não se focam em enfrentar as raízes e as ambiguidades das dinâmicas de mercantilização e de financeirização da habitação e da própria vida urbana (Rossi, 2017). Em particular, a generalizada transição da oferta imobiliária para a oferta turística e para a especulação imobiliária de escala, entretanto globalizada, pode dificilmente ser invertida ou, pelo menos, melhor gerida com foco em objetivos públicos, sem uma forte capacidade de regulação e - em determinados casos - sem intervenção direta de base estatal. Isto é verdade especialmente no momento em que o país ainda se encontra, apesar da gradual recuperação econômica, em tempos de "pós-austeridade", com 0 advento de uma nova economia, mas de rendimentos ainda instáveis e com as capacidades financeiras da maioria das famílias ainda relativamente fracas. Assim, a "competição" entre investidores com forte capacidade de despesa - e com relevantes benefícios fiscais ao investimento - e os (aspirantes a) residentes resulta ainda muito desequilibrada. Aliás, essas tendências desequilibradas não se têm limitado a Lisboa, sendo crescentemente evidentes nas outras cidades, desde logo o Porto, e ainda em cidades médias (Esteves, 2016; Lopes, 2017), tendo-se, assim, essa questão se tornado um problema de escala nacional.

Finalmente, os desequilíbrios e as tensões entre os elementos de abertura e de ausência parecem resultar num panorama de contradições, especialmente evidente para a cidade de Lisboa. Desde logo, o Presidente da Câmara e diversas entidades municipais não cessam de insistir na necessidade de continuar a atrair mais turistas, ${ }^{37}$ ao mesmo tempo que explicitam a preocupação com as dificuldades de acesso à habitação e ao arrendamento. 0 próprio Programa de Renda Acessível, colocado como central para as estratégias municipais de apoio à habitação e com metas ambiciosas, parece ser um bom exemplo dessas contradições. Por um lado, o elevado interesse despoletado entre os gestores de fundos imobiliários ${ }^{38}$ sugere que o programa pode correr o risco de se tornar mais uma componente do processo de financeirização do património habitacional da 
cidade através da construção de parcerias público-privadas. Por outro lado, o governo municipal de Lisboa tem preferido até agora apostar em novas construções (consideradas área de atuação quase exclusiva dos atores privados. Ver Tulumello, 2016) em vez de concentra-se em projetos de requalificação e reconversão urbanística centrada na mixité social. Essas contradições têm sido evidentes na gestão do amplo património imobiliário detido pela Câmara. Por exemplo, no programa "Reabilita Primeiro, Paga Depois", em função do qual o governo municipal tem vendido (quase exclusivamente a investidores profissionais) edifícios habitacionais em localizações privilegiadas da cidade (Bivar et al., 2017), mostrando a intenção de ceder - no médio prazo - parte relevante de habitações de propriedade municipal (UrbanGuru, 2011).

Os cenários desenhados até agora (que potencialmente poderiam mudar, embora não haja serias indicações de que uma mudança de rumo esteja a tomar forma em breve) parecem revelar a inexistência de uma visão interescalar (que conecte medidas de âmbito local, nacional e mesmo Europeu) para enfrentar os sérios fundamentos da crise de habitação na principal cidade portuguesa. Ao mesmo tempo, a recentíssima adesão da Câmara de Lisboa ao manifesto da rede Cities for Adequate Housing (ver introdução) poderá assinalar a assumpção de uma certa mudança de atitude. Se essa atitude local se materializar em ações concretas, conjuntamente com as reformas nacionais em curso, é possível que as aberturas que mencionamos possam consolidar-se numa nova dinâmica política e dar forma a políticas consequentes capazes de diminuir as ausências bem como reequilibrar as contradições - que acima realçamos. Nesse quadro, o futuro da situação habitacional de Lisboa parece estar, assim, "radicalmente aberto". ${ }^{39}$

\section{Conclusões, em movimento}

Perante a crescente reestruturação planetária decorrente da nova era digital, tem-se acelerado um paralelo movimento de cristalização de uma sociedade urbana, com as suas novas realidades e problemáticas - um movimento já anunciado há décadas, na verdade, por pensadores como Henri Lefébvre, Manuel Castells, Edward Soja ou David Harvey.

Tal movimento de carácter histórico - ou de "tempos longos" - tem provocando a necessidade vital de uma repolitização das arenas urbanas e do reposicionamento dos seus desafios, de ordem muito mais transversal (Merrifield, 2013; Moulaert et al., 2013). Para os sistemas urbanos que já evidenciavam dificuldades econômicas e políticas de ordem estrutural, e que hoje apresentam elevados desequilíbrios nessa transição - como são, de forma evidente, muitas cidades e metrópoles do Sul da Europa, incluindo o caso de Lisboa (Seixas e Albet, 2012) -, essa transformação histórica tem-se sucedido em simultâneo com os impactos de uma profunda crise económica e de um deliberado redireccionamento dos capitais privados e públicos e das políticas redistributivas. 0 que tem resultado em paisagens socioeconómicas urbanas crescentemente ambíguas, nas quais, a par de interessantes dinâmicas de transição econômica e ecológica, sucedem-se novas incertezas na sustentação da qualidade de vida e mesmo diversos focos de aumento das desigualdades socioespaciais e dos direitos 
urbanos. 0 setor da habitação, em particular e na verdade, como sempre, dado o seu carácter de ativo primordial tanto em nível sociourbano como econômico-financeiro - coloca-se como uma área extremamente sensível perante essas transformações e perante, sobretudo, os evidentes desequilíbrios na capacidade política de governação nesta era de transição.

Tal efeito, entendido de forma incremental pela sociedade urbana, tem sobrelevado uma crescente reação social e o posicionamento de novos movimentos sociais urbanos com propostas cada vez mais consistentes de alterações de políticas e atitudes institucionais. Sobretudo nas escalas mais locais, embora sustentados em princípios transversais de defesa do património urbano coletivo e dos bens comuns (Blanco e Gomá, 2016; Foster e laione, 2016).

Por seu lado, as mudanças em curso na vida urbana não poucas vezes sentidas pelo cidadão de forma paradoxal ou mesmo ubíqua (Rossi, 2017); situam-se igualmente na reestruturação das próprias percepções sociais e políticas de coesão, de inclusão e de qualidade de vida e, enfim, da própria percepção dos direitos e do exercício de cidadania (Mattei, 2011; Subirats, 2016). A conjugação dessas tendências tem acentuado as ambivalências da vida urbana e a evidente fragilização do capital social "clássico".

Essa fragilidade é visível na estruturação dos novos movimentos sociais de cariz urbano. Mas apenas se interpretada à luz das noções mais clássicas de capital social. Pois, na verdade, o espaço público da política urbana tem sido crescentemente ocupado - nas principais cidades europeias, e com alguma defasagem também em Lisboa - por novos perfis de capital social, de cidadania e de intervenção; sobretudo nas classes mais jovens e muito mais digitalizadas, num interessante "efeito-urbanidade" latente nas expressões cívicas.

Portugal encontra-se, presentemente, num evidente caminho de transição socioeconómica. ${ }^{40}$ Vai-se situando - apesar das resistências decorrentes de uma enraizada cultura de path-dependency quer na sociedade e economia, quer na própria administração pública - uma crescente abertura para novos processos e agentes de progresso. Estando o território, e notavelmente as cidades e a vida urbana, a ganhar posicionamento político. $\mathrm{E}$ a serem crescentemente reconhecidos os impactos que as políticas económicas provocam nestas. Nas questões mais relacionadas com a habitação, e num panorama já em certa tendência pós-autoritária da política portuguesa, a cidade de Lisboa (e seus movimentos sociais) tem desempenhado um importante papel de catalisador para tornar os problemas e as possíveis propostas mais visíveis. As abordagens políticas dos atuais governantes mostram ser, finalmente, mais abertas para a auscultação e mesmo para a negociação com uma gama mais ampla de atores do terreno. Se bem que seja ainda muito evidente a variabilidade de atitudes políticas nos diferentes fóruns e instituições - o que traduz muitas incertezas, ainda para mais em face das forças em contradição de estratégias -, está não obstante já relativamente longe o fecho autorreferencial que caracterizou o passado recente.

A mudança de atitudes em nível nacional, paulatinamente desenvolvida desde 2015, é sem dúvida resultado de transformações políticas e, particularmente, de uma nova centralidade da política parlamentar; mas também 
resultado do crescente posicionamento de novos movimentos sociais de cariz urbano. Estes têm sido mesmo relevantes para a própria concepção (ainda em aperfeiçoamento) da Nova Geração de Políticas de Habitação. Não obstante, essas políticas parecem estar longe de constituir-se como uma robusta política pela habitação e falta, ainda, ação em setores paralelos mais igualmente fundamentais para políticas de coesão e redistribuição social e urbana, tais como nos setores do urbanismo e da gestão dos fluxos turísticos. 0 que, em relevante medida, faz com que as políticas públicas estejam ainda muito dependentes das (frágeis) capacidades de intervenção das autoridades locais (Henriques e Pinto, 2018). Estas, por sua vez, mantêm atitudes de frequente ambiguidade ou mesmo contradição, sobretudo perante fileiras económicas decisivas, tais como o setor do turismo.

Em Lisboa, por um lado, existem claros elementos que comprovam a dispersão das comunidades, através da fragmentação e da financeirização da vida metropolitana, bem como da atomização social trazida pela dimensão digital, do vórtice das pressões imobiliárias e, ainda, dos descompassos funcionais resultantes da consolidação das novas estruturas de trabalho e de mobilidade. Porém, por outro lado, é possível observar novas dinâmicas de reagregação comunitárias baseadas na evidente (re)valorização da cidade e da vida urbana e na valorização da ecologia humana e biofísica, especialmente visível nas novas gerações (Fuster Morell, 2013). Especialmente, nota-se como o paulatino reforço das políticas públicas de proximidade tem também despertado um leque variado de reacções dos cidadãos e dos movimentos sociais para com a transformação das dinâmicas económicas e organizacionais dos seus territórios de vida quotidiana.

Dada a relevância da cidade-capital na formação do pensamento sociopolítico nacional - ao que também se juntam os movimentos sociais igualmente em vivo dinamismo na segunda cidade do Porto -, bem como a participação de agentes culturais de alguma relevância, e, ainda, uma importante e crescente interligação com redes internacionais de movimentos similares; os movimentos sociais de Lisboa e suas reivindicações e propostas têm vindo a tomar um papel que mostra ir além das soluções específicas para os territórios onde mais actuam. Tem-se defendido uma gama relativamente ampla de reformas estruturais; que vão das múltiplas propostas para o fomento do setor da habitação; a uma muito mais atenta gestão e regulação local das actividades turísticas; a propostas de revisão fiscal nos investimentos financeiros e territoriais; e, enfim, à revisão dos desequilíbrios ainda existentes decorrentes do Regime de Arrendamento Urbano.

Ao mesmo tempo, diferentes propostas convergem no sentido de melhores garantias de que uma parte relevante dos ganhos econômicos relacionados com as novas fileiras mais dinâmicas - e notavelmente o setor turístico, mas não somente - possa ser redistribuída para bens públicos e comuns inerentes aos territórios locais e às comunidades mais diretamente envolvidas com as alterações dos seus fluxos.

A necessidade de abordagem a essas questões de forma mais política levanta, por sua vez, um outro denominador comum importante: a necessidade de produção de informação e de conhecimento, de forma mais permanente e muito mais fina, sobre as mais 
diversas questões interligadas com a habitação, com as novas formas de vivência urbana, com as estratégias e regulamentos de planejamento e de uso do solo e de propriedade. Essas sugestões são um bom exemplo que mostra como uma capacidade efectiva de enfrentar os novos problemas de habitação nas áreas urbanas será fortemente influenciada pela capacidade de outras reformas mais transversais, ainda consideravelmente incertas no atual quadro político português.

Essas fragilidades - ou desequilíbrios são particularmente sentidos, no nosso entender, em face do que chamamos na secção anterior de contradições entre os elementos de abertura e, por sua vez, os elementos de ausência, no posicionamento das políticas de habitação e, em nível mais global, das políticas urbanas em Portugal. Tais desequilíbrios são também sentidos - embora por formas distintas - nos próprios movimentos sociais. Mas estamos acreditando que, seguramente, uma crescente capacidade, a par de uma desejada coerência democrática, das redes de ativismo social na atenção crítica e influência política nas sérias transformações em curso, será, no nosso entender, fundamental - como revelou ser nos anos mais recentes - para as potenciais transições de reforçados dínamos de ação política urbana.

\section{[I] https://orcid.org/0000-0002-4948-9113}

Universidade Nova de Lisboa, Centro Interdisciplinar de Ciências Sociais. Lisboa, Portugal. jseixas@fcsh.unl.pt

\section{[II] https://orcid.org/0000-0002-6660-3432}

Universidade de Lisboa, Instituto de Ciências Sociais. Lisboa, Portugal.

simone.tulumello@ics.ulisboa.pt

\section{[III] https://orcid.org/0000-0001-6234-5168}

Universidade de Coimbra, Centro de Estudos Sociais. Coimbra, Portugal. University of the Witwatersrand, School of Architecture and Planning. Joanesburgo, África do Sul. giovanni.allegretti@ces.uc.pt

\section{Agradecimentos}

Os autores agradecem, à Priscila Soares, pela revisão do texto. Simone Tulumello agradece o suporte da Fundação para a Ciência e Tecnologia (SFRH/BPD/86394/2012 e PTDC/GES-URB/28826/2017). 


\section{Notas}

(1) Instituição independente de análise dos mercados do solo. Ver https://confidencialimobiliario. com/.

(2) Ver https://www.airdna.co/market-data/app/pt/lisboa/lisbon/overview .

(3) Ver www.lisboarendaacessivel.pt/inicio.html.

(4) Ver https://citiesforhousing.org.

(5) A palavra é um neologismo, que sublinha a combinação de medidas econômicas e financeiras de austeridade com uma tendência de governo autoritária e pouco aberta ao diálogo com a sociedade civil e com outras forças políticas.

(6) O Programa de Ajustamento Económico para Portugal consistiu num pacote de assistência financeira solicitado, em 2011, pelo então governo socialista devido a uma profunda crise da dívida soberana, bem como num Memorando de Entendimento relativo a uma série de reformas, solicitadas em troca de resgate de 78 bilhões de euros recebidos. O programa trienal foi assinado em maio de 2011 pelo governo e pela chamada Troika, formada pelo Fundo Monetário Internacional, pelo Banco Central Europeu e pela Comissão Europeia. Foi implementado, principalmente, durante os governos liderados pelo Partido Social-Democrata (que, em Portugal, é o nome de um partido de centro-direita) coordenado pelo Primeiro Ministro, Passos Coelho.

(7) Ver, para uma discussão das respostas governamentais locais na área metropolitana de Lisboa, Seixas et al. (2015). E, para um quadro de mobilizações cívicas, ver Accornero e Pinto (2015).

(8) Outros autores, como Moury e Standring (2017), também insistiram na exploração estratégica do resgate que foi feita pelas elites nacionais, para ganhar poder sobre outros atores.

(9) Por exemplo, a liberalização do sistema de planeamento e a flexibilização dos regulamentos de proteção laboral.

(10) Ver https://ces.uc.pt/observatorios/crisalt/.

(11) Portugal - como evidenciado pelos dados Eurostat para 2016 - tem o investimento público mais baixo em relação ao PIB em toda a União Europeia. De facto, ele caiu de 2,2\% do PIB em 2015 para 1,5\% em 2016 e atingiu 1,8\% em 2017. Os gastos com saúde pública caíram de 6,9\% do PIB em 2009 para 5,9\% em 2016. Nos gastos com educação (que se deram enquanto a população estudantil diminuía), houve uma queda para $4,9 \%$ do PIB (queda de $0,2 \%$ ) no mesmo período.

(12) De acordo com o Eurostat, os juros pagos pelo governo caíram de 4,6\% do PIB em 2015 para 3,9\% em 2017, enquanto - do lado da receita - os 25 bilhões de euros de títulos da dívida pública comprados pelo Banco de Portugal sob QE foram sendo devolvidos ao Tesouro como dividendos do Banco de Portugal (Teles, 2018). Trata-se, apenas em 2017, de 525 milhões de euros que representam quase $0,3 \%$ do PIB.

(13) Se - conforme já vimos - o investimento público é baixo e minguante, algo parecido se pode também dizer do investimento agregado (ou seja, público e privado), que rondou $16,1 \%$ do PIB para 2017, ainda bem abaixo do nível pré-crise de 2008, que era de $22,8 \%$ (Teles, 2018). 
(14) De acordo com o Eurobarómetro, a confiança no parlamento nacional caiu entre 2009 (quando $38 \%$ dos portugueses declararam confiar nele) e 2013 (14\%); depois recuperou rapidamente (44\% em 2017). Ver http://ec.europa.eu/commfrontoffice/publicopinion/index.cfm/Chart/ getChart/chartType/lineChart//themeKy/18/groupKy/89/savFile/867.

(15) As chamadas freguesias são autarquias administrativas autónomas cujos organismos políticos são eleitos pela população e em simultâneo com as eleições municipais.

(16) Os prêmios recebidos por Portugal foram 37, em 2017, 13 a mais do que em 2016 (cerca de 30\% do total de prêmios distribuídos em nível global).

(17) O Estatuto de Residente Não Permanente, disponível para qualquer pessoa que não tenha sido residente fiscal em Portugal durante os cinco anos anteriores, isenta de tributação em Portugal por um período (renovável sob certas condições) de 10 anos.

(18) O alojamento estudantil parece ser "o próximo grande lucro" para o investimento imobiliário, como sugerido pelo estudo encomendado à start-up local Uniplaces pela Jones Lang LaSalle (ver JLL, Uniplaces, 2018).

(19) O regime dos Golden Visa (ou Autorização de Residência para Investimento) permite, aos nacionais de países terceiros, obter uma autorização de residência temporária para exercerem atividades com isenção de visto para entrar no território nacional e no Espaço Schengen. Embora o plano estivesse teoricamente previsto para outros investimentos, além do imobiliário (investimentos de capital para criação de emprego, financiamento de instituições de pesquisa, artes locais, património nacional, compra de participações em fundos de investimento ou capital de risco destinado a capitalizar pequenas e médias empresas em Portugal), entre 2012 e 2018, 94\% dos vistos foram concedidos a investidores em imóveis (SEF, 2019).

(20) Para estimativas demográficas do Instituto Nacional de Estatística, ver: www.ine.pt/xportal/ xmain?xpid=INE\&xpgid=ine_base_dados\&contexto=bd\&selTab=tab2.

(21) Nesse caso, falamos por experiência direta, estando ativamente envolvidos nas atividades dalguns desses grupos. Como exemplo, a clínica de aconselhamento do Habita, para pessoas em risco de despejo, apoiou mais famílias nos primeiros quatro meses de 2018 do que nos cinco anos anteriores.

(22) Por exemplo, a cidade da Amadora, no primeiro anel suburbano, registou, em 2017, o maior crescimento dos preços da habitação do país (INE, 2018).

(23) Ver http://moraremlisboa.org/.

(24) Ver www.caracoldapenha.info/.

(25) Ver https://quotadehabitacaocomum.wordpress.com/

(26) Verhttps://www.facebook.com/Terra\%C3\%A7o-do-Pr\%C3\%A9dio-dos-Anjos-854213204734679/

(27) 64 mil habitantes em gestão municipal (cf. www.gebalis.pt/Geral/SobreGebalis/DadosEmpresa/ Paginas/DadosdaEmpresa.aspx), no contexto da dimensão dessa tipologia de bairros na cidade, há que acrescentar, ainda, os do movimento cooperativo e SAAL, e os geridos por instituições estaduais e privadas não lucrativas; ou seja, a proporção é bem maior do que um sétimo. 
(28) O projeto "exPERts. Making Sense of Planning Expertise" (https://expertsproject.org/), em curso desde 2016, e dois projetos em curso desde 2018: "HOPES: Housing Struggles and Perspectives" (liderado pelo CIES-IUL) e "SustainLis: Sustainable urban requalification and vulnerable populations in the historical centre of Lisbon".

(29) Ver https://expertsproject.org/2017/12/21/forum-da-habitacao-8-janeiro-2018-ics-ulisboa/ e https://expertsproject.org/2018/03/29/segundo-forum-da-habitacao-ics-ulisboa-5-de-abril$14 \mathrm{~h} 30 /$.

(30) Ver https://www.urbanologo.com/, http://ces.uc.pt/observatorios/crisalt, https://www. facebook.com/Laboratório-de-Habitação-Básica-ParticipadaBasic-Housing.

(31) Ver https://caravanapelahabitacao.wordpress.com e https://stopdespejos.wordpress.com/.

(32) Ver http://afectadosporlahipoteca.com/.

(33) Ver www.portugal.gov.pt/pt/gc21/area-de-governo/ambiente/secretarios-de-estado\#Habitacao.

(34) São já aprovados: as orientações estratégicas (resolução do Conselho de Ministros n. 50-A/2018) e os programas 10 Direto - Programa de Apoio ao Acesso à Habitação (decreto-lei n. 37/2018), Porta de Entrada - Programa de Apoio ao Alojamento Urgente (decreto-lei n. 29/2018), Chave na Mão - Programa de Mobilidade Habitacional para a Coesão Territorial (resolução de Conselho de Ministros n. 57/2018), da Habitação ao Habitat (resolução de Conselho de Ministros n. 56/2018) e o Programa de Arrendamento Acessível (lei n. 2/2019 e lei n. 3/2019). Estão em preparação as alterações legislativas em matéria de arrendamento urbano.

(35) Ver http://habitacao.ps.pt/wp-content/uploads/2018/04/projeto-de-Lei-bases-dahabita\%C3\%A7\%C3\%A3o-GPPS-19.4.2018.pdf.

(36) Ver as declarações do presidente da Câmara Municipal, Fernando Medina, numa entrevista recente https://www.rtp.pt/play/p4258/e355033/grande-entrevista.

(37) Ver uma entrevista recente em https://www.rtp.pt/play/p4258/e355033/grande-entrevista.

(38) De acordo com Rui Coelho, Diretor Executivo da agência gestora do programa Aluguer Acessível em Lisboa (ver http://www.lisboarendaacessivel.pt/inicio.html), a agência já foi contatada por mais de um fundo de investimento interessado em administrar toda a operação, num total de mais de 700 milhões de euros - declarações proferidas recentemente num evento público (Habitação em Foco, 19 de fevereiro de 2018; ver https://youtu.be/XfhCdALalU4).

(39) Expressão (the future is radically open) utilizada pelo geógrafo crítico Neil Smith, na sua última palestra em 2012.

(40) Este reconhecimento sendo feito pelos mais diversos think-tanks bem como pelo próprio Estado e seus mais relevantes documentos de base estratégica, desde o “Portugal 2020" (ver https://www. portugal2020.pt/Portal2020) às estratégias nacionais entretanto em revisão para a preparação do novo quadro Europeu, nas “Estratégias 2030" (ver http://www.portugal2030.pt/). 


\section{Referências}

ABREU, A. et al. (2013). A crise, a troika e as alternativas urgentes. Lisboa, Tinta da China.

ACCORNERO, G. e PINTO, P. R. (2015). 'Mild mannered'? Protest and mobilisation in Portugal under austerity, 2010-2013. West European Politics, v. 38, n. 3, pp. 491-515.

ALLEGRETTI, G. (2018). "When citizen participation unexpectedly grows in quality and quantity: a side effect or an inherent consequence of «austeritarian» approaches?" In: DAVID, I. (org.). Crisis, austerity, and transformation. How disciplinary neoliberalism is changing Portugal. Londres, Lexington.

ALLEN, J. et al. (2004). Housing and welfare in Southern Europe. Oxford, Blackwell.

BANCO DE PORTUGAL (2018). Relatório de Estabilidade Financeira Junho 2018. Disponível em: https:// www.bportugal.pt/sites/default/files/anexos/pdf-boletim/ref_06_2018_pt.pdf. Acesso em: 15 jan 2019.

BIVAR, M. et al. (2017). Reabilita primeiro. Ganha depois. Esquerda.net, n. 29 sep. Disponível em: www.esquerda.net/artigo/reabilita-primeiro-ganha-depois/51169. Acesso: em 15 jan 2019.

BLANCO, I. e GOMÁ, R. (2016). El Municipalisme del Bé Comú. Barcelona, Icaria Editorial.

BLAS, A. e IBARRA, P. (2006). La participación: estado de la cuestión. Cuadernos de Trabajo de Hegoa, n. 39.

CARITAS PORTUGUESA, CARITAS EUROPA (2017). The Young in Europe Need a Future. Caritas Cares Portugal Report, September. Disponível em: http://www.caritas.eu/wordpress/wp-content/ uploads/2018/08/171106-PU-Caritas-cares-youth-poverty-country-report-portugal.pdf. Acesso em: 15 jan 2019.

COLETIVO POLÍTICA EN RED (2007). Repensar la política: en la era de los movimientos y de las redes. Barcelona, Icaria.

COSTA, P. et al. (2017). Estratégias para a Cultura da Cidade de Lisboa 2017. Lisboa, EGEAC/CML.

COSTA, R. (2017). Envelhecimento e rendas altas roubam jovens adultos a Lisboa. Publico, n. 17 set. Disponível em: www.publico.pt/2017/09/17/local/noticia/preco-das-rendas-empurra-jovenspara-fora-de-lisboa-1785448. Acesso em: 15 jan 2019.

DIAS, N. (2017). Orçamentos Participativos em Portugal - Da escolha de projectos à definição de políticas públicas. Le Monde Diplomatique - Edição Portuguesa. Aug, pp. 4-5.

(2018). Hope for democracy. 30 years of Participatory Budgeting worldwide. São Bras de Alportel, In Loco.

EC (EUROPEAN COMMISSION) (2011). The Economic Adjustment Programme for Portugal. Occasional Papers, n. 79.

ESTEVES, M. (2016). Casas para arrendar desaparecem do mercado. Jornal de Negócios. 8 aug. Disponível em: www.jornaldenegocios.pt/economia/rendas/detalhe/casas-para-arrendardesaparecem-do-mercado. Acesso em: 15 jan 2019. 
FAHRA, L. (2017). Report of the Special Rapporteur on adequate housing as a component of the right to an adequate standard of living, and on the right to non-discrimination in this context Mission to Portugal. Disponível em: http://ap.ohchr.org/documents/dpage_e.aspx?si=A/HRC/34/51/Add.2. Acesso em: 15 jan 2019.

FERREIRA, B. (2018). PS e Costa sobem mas geringonça cai. Correio da Manhã. 12 jan. Disponível em: www.cmjornal.pt/politica/detalhe/ps-e-costa-sobem-mas-geringonca-cai?Ref=DET_ noticiasceccao. Acesso em: 15 jan 2019.

FOSTER, S. R. e IAIONE, C. (2016). The city as a commons. Yale Law and Policy Review, v. 34, n. 281, pp. 281-349.

FREIRE, A. (2017). Para lá da "Geringonça". Lisboa, Edições Contraponto.

FUSTER MORELL, M. (2013). “Online creation communities viewed through the analytical framework of the institutional analysis and development". In: MADISON, M. J.; STRANDBURG, K. e FRISCHMANN, B. (orgs.). Convening Cultural Commons. Oxford, Oxford University Press.

HARVEY, D. (2006 [1982]). The limits to capital. Londres, Verso.

HENRIQUES, J. (2016). Isto é produção cultural massiva de Lisboa. Ípsilon/Público, 20 mai. Disponível em: www.publico.pt/2016/05/20/culturaipsilon/noticia/isto-e-producao-cultural-massiva-delisboa-1732128. Acesso em: 15 jan 2019.

HENRIQUES, J. e PINTO, L. (2018). “A nossa velocidade agora vai ser a dos municípios”. Público, 4 maio. Disponível em: www.publico.pt/2018/05/04/sociedade/entrevista/a-nossa-velocidade-agoravai-ser-a-dos-municipios-1825065. Acesso em: 15 jan 2019.

IHRU (INSTITUTO DE HABITAÇÃO E REABILITAÇÃO URBANA) (2015). 1987-2011. 25 Anos de Esforço do Orçamento do Estado com a Habitação. Disponível em: http://www.portaldahabitacao.pt/ opencms/export/sites/portal/pt/portal/publicacoes/estudos/Esforco-do-Estado-em-Habitacao. pdf. Acesso em: 15 jan 2019.

(2018). Levantamento Nacional das Necessidades de Realojamento Habitacional. Disponível em: https://www.portaldahabitacao.pt/opencms/export/sites/portal/pt/portal/habitacao/ levantamento_necessidades_habitacionais/Relatorio_Final_Necessidades_Realojamento.pdf. Acesso em: 15 jan 2019.

INE (INSTITUTO NACIONAL DE ESTATISTICA) (2018). Estatísticas de Preços da Habitação ao nível local 3o trimestre de 2017. Disponível em: www.ine.pt/ngt_server/attachfileu.jsp?look_ parentBoui=317157010\&att_display=n\&att_download=y. Acesso em: 15 jan 2019.

JLL, UNIPLACES (2018). Portugal Student Housing. 2017 report. Disponível em: www.jll.pt/portugal/ptpt/Research/AF_Portugal_Student\%20Housing_lado\%20a\%20lado.pdf. Acesso em: 15 jan 2019.

LOPES, B. (2017). Airbnb em números (e dois mapas incríveis). 2 jun. Disponível em: www.sabado.pt/ dinheiro/detalhe/airbnb-em-numeros-e-dois-mapas-incriveis. Acesso em: 15 jan 2019.

LUSA (2017). António Costa elege políticas para habitação acessível como «nova prioridade». Público. 17 jun. Disponível em: https://www.publico.pt/2017/06/17/politica/noticia/antonio-costa-elegepoliticas-para-habitacao-acessivel-como-nova-prioridade-1776021. Acesso em: 15 jan 2019.

MADDEN, D. e MARCUSE, P. (2016). In defense of housing. The politics of crisis. Londres, Verso. 
MALHEIROS, J.; CARVALHO, R. e MENDES, L. (2013). Gentrification, residential ethnicization and the social production of fragmented space in two multi-ethnic neighbourhoods of Lisbon and Bilbao. Finisterra, n. 96, pp. 109-135.

MARUJO, M. (2018). Bloco quer saber impacto de vistos gold na especulação imobiliária. Diario de Notícias, 23 jun. Disponível em: https://www.dn.pt/portugal/interior/bloco-quer-saber-impactode-vistos-gold-na-especulacao-imobiliaria-9500665.html. Acesso em: 15 jan 2019.

MATTEI, U. (2011). Beni comuni: un manifesto. Roma, Laterza.

MERRIFIELD, A. (2013). The urban question under planetary urbanization. International Journal of Urban and Regional Research, v. 37, n. 3, pp. 909-922.

MINDER, R. (2018). Lisbon Is thriving. But at what price for those who live there? New York Times, 23 maio. Disponível em: www.nytimes.com/2018/05/23/world/europe/lisbon-portugal-revival. html?smtyp=cur\&smid=tw-nytimesworld. Acesso em: 15 jan 2019.

MOULAERT, F. et al. (orgs.) (2013). The International Handbook of Social Innovation. Cheltenham, Edward Elgar.

MOURY, C. e STANDRING, A. (2017). "Going beyond the Troika": Power and discourse in Portuguese austerity politics. European Journal of Political Research, v. 56, n. 3, pp. 660-679.

NEL.LO, O. (2015). La ciudad en movimiento. Madrid, Diaz \& Ponz.

PEDROSO, P. (2014). Portugal and the global crisis: The impact of austerity on the economy, the social model and the performance of the state. Berlim, Friederich Ebert Stiftung.

ROSSI, U. (2017). Cities in Global Capitalism. Londres, Polity Press.

ROSSI, U. e TULUMELLO, S. (2018). A capital, cidade-metrópole no capitalismo de tecnologia avançada. Le Monde Diplomatique - Edição Portuguesa, Apr, pp. 6-7.

SEF (SERVIÇOS ESTRANGEIROS E FRONTEIRAS) (2019). Autorização de Residência para atividade de Investimento (ARI). Dados de 08 de outubro de 2012 a 31 de dezembro de 2018. Disponível em: https://www.sef.pt/pt/Documents/Mapa_ARI_PT_dezembro18.pdf. Acesso em: 15 jan 2019.

SEIXAS, J. (2013). A cidade na encruzilhada. Repensar a cidade e a sua política. Porto, Afrontamento.

SEIXAS, J. e ALBET, A. (eds.) (2012). Urban Governance in Southern Europe. Londres, Ashgate.

SEIXAS, J. e GUTERRES, A. B. (2018). Political evolution in the Lisbon of the digital era. Fast urban changes, slow institutional restructuring and growing civic pressures. Urban Research and Practice. Latest articles. Disponível em: https://doi.org/10.1080/17535069.2018.1505272.

SEIXAS, J.; MAGALHÃES, A. e COSTA, P. (2013). "Os tempos novos do centro histórico de Lisboa". In: FERNANDES J. A. R. e ESPOSITO, M. E. (orgs.). A vida nova nos velhos centros históricos de Portugal e do Brasil. Porto, Edições Cegot.

SEIXAS, J. e MARQUES, T. S. (2015). “O Território e as Cidades em Portugal. Filhos de um Deus menor?”. In: Conferência Gulbenkian 2014: Afirmar o Futuro - Políticas públicas para Portugal. Lisboa, Fundação Calouste Gulbenkian.

SEIXAS, J. et al. (2015). Dinâmicas sociogeográficas e políticas na Área Metropolitana de Lisboa em tempos de crise e de austeridade. Cadernos Metrópole. São Paulo, v. 17, n. 34, pp. 371-399. 
SILVA, R. (2017). A nova geração de políticas de habitação que não evita a expulsão das nossas casas e dos nossos lugares. Habita. 5 out. Disponível em: www.habita.info/2017/10/a-nova-geracao-depoliticas-de.html. Acesso em: 15 jan 2019.

SUBIRATS, J. (2016). El poder de lo próximo. Las virtudes del municipalismo. Madrid, Los Libros de la Catarata.

TELES, N. (2018). The Portuguese Illusion. Jacobin, 2 jul. Disponível em: https://jacobinmag. com/2018/07/portugal-left-bloc-eurozone-austerity-eu. Acesso em: 15 jan 2019.

TIAGO, L. (2017). Estado da Nação: António Costa cria Secretaria de Estado da Habitação. DinheiroVivo. 12 jul. Disponível em: www.dinheirovivo.pt/economia/antonio-costa-leva-amanha-a-belemremodelacao-do-governo. Acesso em: 15 jan 2019.

TULUMELLO, S. (2016). Reconsidering neoliberal urban planning in times of crisis: urban regeneration policy in a «dense» space in Lisbon. Urban Geography, v. 37, n. 1, pp. 117-140.

TULUMELLO, S. et al. (2018). Comparative planning and housing studies beyond taxonomy: a genealogy of the special programme for rehousing (Portugal). Transactions of AESOP, v. 2, pp. 32-46.

URBANGURU (2011). Programa de Intervenção Estratégica no Património Habitacional Municipal e nos Devolutos Municipais. Relatório final. Disponível em: http://habitacao.cm-lisboa.pt/docume ntos/1323729521D4qVS7sI3Eu87LY5.pdf. Acesso em: 15 jan 2019.

Texto recebido em 12/nov/2018

Texto aprovado em 20/dez/2018 